\title{
Una propuesta desde Prensa Escuela para formarse y transformar*
}

\author{
Sonia Amparo Guerrero Cabrera ${ }^{1}$ \\ Mariana Acosta Gutiérrez ${ }^{2}$ \\ Carolina Campuzano Baena ${ }^{3}$
}

Recibido: 22-05-2020

Aceptado: 05-07-2020

\section{Resumen}

Se expone una descripción de las principales estrategias pedagógicas del programa Prensa Escuela de Medellín, que se identificaron en la investigación "La mediación de Prensa Escuela en la formación ciudadana y la ética", realizada en convenio entre la Universidad Pontificia Bolivariana, la Universidad de San Buenaventura y el periódico El Colombiano. Por medio de una metodología cualitativa y de revisión documental se analizaron las producciones escritas de la publicación anual del programa denominada El Taller (2012-2016), para establecer los procedimientos y estrategias relacionados con los objetivos claves, que son: lectura con criterio

\footnotetext{
* Este artículo de reflexión se construye a partir de los hallazgos de la investigación "La mediación de Prensa Escuela en la formación ciudadana y la ética", del grupo de investigación ESINED, de la Universidad de San Buenaventura, aprobada en convocátoria interna y culminada en 2018; se realizó en convenio con el periódico El Colombiano en el marco del programa Prensa Escuela.
}

1. Magíster en Hermenéutica Literaria. Docente investigadora, Universidad de San Buenaventura - Facultad de Educación. Miembro del grupo de investigación Estudios Interdisciplinarios en Educación (ESINED). Investigadora júnior (Colciencias). Coordinadora del convenio Prensa Escuela de la Facultad de Educación de la Universidad de San Buenaventura.

Correo electrónico: sonia.guerrero@usbmed.edu.co CvLAC: https://cutt.ly/Zfr8jO4

ORCID: https://orcid.org/0000-0001-9176-0029

Google Scholar: https://scholar.google.com/citations?hl=en\&user=hEjSR-MAAAAJ

2. Auxiliar de investigación del Convenio Prensa Escuela, Facultad de Educación. Estudiante de Licenciatura en Humanidades y Lengua Castellana, Universidad de San Buenaventura.

Correo electrónico: mariana.acostagutierrez98@gmail.com

CvLAC: https://cutt.ly/7ftwgSk

ORCID: https://orcid.org/0000-0002-0582-3052

3. Periodista y comunicadora social. Docente de la Universidad Pontificia Bolivariana. Coordinadora del convenio Prensa Escuela de la Facultad de Comunicación y Periodismo, Universidad Pontificia Bolivariana.

Correo electrónico: carolina.campuzano@upb.edu.co

CVLAC: https://cutt.ly/JftgeEc

ORCID: https://orcid.org/0000-0002-7495-3336

Google Scholar: https://scholar.google.com/citations?user=GuTi9icAAAAJ\&hl=en 
y producción de contenidos responsable. Así, se encontró que las estrategias pedagógicas sobre ética comienzan con la reflexión sobre sí mismo, y se relacionan con la interpretación de la realidad para el favorecimiento de la autonomía; en cuanto a la formación ciudadana, el reconocimiento del territorio, la problematización de la realidad y la narración son los asuntos claves para su fortalecimiento.

Palabras clave: comunicación, estrategias pedagógicas, formación, ciudadanía, ética, jóvenes.

\section{A proposal from Prensa Escuela to form and transform}

\section{Abstract}

A description of the main pedagogical strategies of the Prensa Escuela Program of Medellín is exposed, which were identified in the research: Mediation of the Prensa Escuela in citizen training and ethics, carried out in agreement between the Universidad Pontificia Bolivariana, the Universidad of San Buenaventura and the newspaper El Colombiano. Through a qualitative methodology and documentary review, the written productions of the annual publication of the Program called El Taller (2012-2016) were analyzed to establish the procedures and strategies related to the key objectives, which are: criteria reading and production of responsible content. Thus, it was found that pedagogical strategies on ethics begin with reflection on oneself, are related to the interpretation of reality for the promotion of autonomy; as for citizen training, the recognition of the territory, the problematization of reality and narration are the key issues for its strengthening.

Keywords: communication, pedagogical strategies, training, citizenship, ethics, young people. 


\section{Introducción}

Prensa Escuela funciona en la ciudad de Medellín como un programa de responsabilidad social del periódico El Colombiano, que en convenio con la Universidad Pontificia Bolivariana y la Universidad de San Buenaventura realizan diferentes actividades de formación con niños, jóvenes, maestros, bibliotecarios y demás interesados por la lectura y la escritura como herramientas de comprensión del mundo y de intervención social. A lo largo de su historia en Antioquia, que se remonta al año 1994, el programa ha desarrollo una serie de actividades de apoyo al ámbito educativo para la formación ciudadana; además, su marco de trabajo ha sido y continúa siendo el protagonismo que el periódico puede alcanzar como medio para construir conocimientos y nutrir de aprendizajes significativos a quienes asisten a los talleres, capacitaciones o conferencias.

La población de impacto va desde el preescolar hasta la universidad, llegando a espacios paralelos como bibliotecas, eventos de promoción de lectura, escuelas normales, entre otros, en los cuales el manejo y, muy importante, el cuestionamiento de la información son la ruta de trabajo para reflexionar sobre la realidad y revisar las acciones cotidianas. En este escenario, la principal actividad del programa consiste en los procedimientos que rodean la publicación anual denominada El Taller.

La estructuración de los escritos que componen El Taller empieza con la convocatoria a jóvenes universitarios de programas de humanidades, estudiantes de las dos universidades vinculadas, a ser parte de Prensa Escuela como talleristas. Después de un proceso de selección, que apunta a identificar fortalezas en conocimientos, destrezas e intereses por los mencionados ejes de trabajo, los jóvenes reciben una capacitación en la cual se cimientan las bases para el posterior desarrollo de talleres con estudiantes de distintos colegios de la ciudad; de esta manera los talleristas, a la vez que tienen una experiencia de re-encuentro con la lectura, la escritura y reflexionan sobre la formación ciudadana, van construyendo actividades y procedimientos que aplicarán más adelante. 
Los estudiantes de los colegios son convocados por sus directivos y por profesores interesados en Prensa Escuela, ya que el programa mantiene una constante comunicación con instituciones educativas para ofrecerles esta modalidad de trabajo, en la cual los estudiantes permanecen por varios meses asistiendo a los talleres.

Entonces, con un grupo consolidado se da inicio al desarrollo de los talleres; en diversas ocasiones los talleristas han acudido a los colegios, donde se les facilita un tiempo y espacio para desarrollar las actividades; en otras ocasiones, los estudiantes de los colegios van a la Universidad Pontificia Bolivariana para la realización de los encuentros. Estas dinámicas van cambiando, dependiendo de las necesidades de la población, ya que el programa busca ante todo brindar una experiencia de formación que enriquezca el horizonte de los asistentes.

La manera de evidenciar y resaltar el sinnúmero de vivencias que los talleristas y los estudiantes tienen a lo largo de su casi un año de trabajo - la duración completa de un ciclo es de febrero a noviembre- es publicando los mejores escritos en El Taller. Dichos textos se construyen a partir de las propuestas metodológicas de los talleristas, quienes aprovechan los elementos pedagógicos y del periodismo abordados en su etapa de capacitación para instruir a los estudiantes en el desarrollo de escritos en el marco de los géneros periodísticos, como la entrevista, la crónica y el perfil, principalmente. La intención es que puedan narrar su realidad de manera no ficcional, para darle relevancia a las vivencias cotidianas que se cuentan dentro y a partir de los talleres.

En este panorama, el equipo de Prensa Escuela busca re-pensar su labor y alcances, elaborando investigaciones que puedan mostrar nuevas perspectivas de las actividades y llegar a construir renovadas estrategias de trabajo. Con el aval del comité de investigación de la Universidad de San Buenaventura y dentro del Grupo de Estudios Interdisciplinarios sobre Educación ESINED, surge el proyecto que da vida a este escrito. 
Así, la investigación "La mediación de Prensa Escuela en la formación ciudadana y la ética" tuvo como objetivo general caracterizar las dos categorías que aparecen en su título, de manera que desde la identificación de las cualidades, formas y detalles de la formación ciudadana y la ética se pueda describir y enunciar vías de trabajo; se recurrió a la investigación cualitativa, que permite el acercamiento a un fenómeno humano complejo, como lo es en este caso la formación; en palabras de Martínez (2006): "la investigación cualitativa trata de identificar la naturaleza profunda de las realidades, su estructura dinámica, aquella que da razón plena de su comportamiento y manifestaciones" (p. 128).

Por medio de la revisión documental y con un método hermenéutico-dialéctico, en primer lugar se sistematizaron los escritos de docentes, talleristas y estudiantes que participaron directamente en los talleres del programa durante un periodo significativo, como lo es del año 2012 al año 2016, reuniendo así un total de 101 textos; luego se hizo un análisis basado en categorías descriptivas devenidas de la revisión teórica, y se establecieron las subcategorías y temas emergentes. Al integrar, comparar y examinar los datos obtenidos se pudieron esclarecer elementos claves respecto a la formación ciudadana y la ética, los procesos de lectura y escritura, y el abordaje de la información dentro del programa, así como las estrategias de trabajo que posibilitan alcanzar los objetivos.

A continuación, se presenta una breve descripción de los conceptos esenciales que fundamentan el desarrollo de las actividades; así, se comienza por el lenguaje como fundamento de toda pedagogía; se explica qué es la formación; seguidamente se expone el modelo de aprendizaje que sostiene al programa; y los siguientes apartados muestran cómo se han configurado las estrategias pedagógicas de Prensa Escuela respecto a las mencionadas categorías centrales: ética y formación ciudadana. Toda esta exposición pretende ser una propuesta de acción, de formación, que aporte a la realidad de un país que como Colombia necesita con urgencia alternativas de vida y crecimiento. 


\section{Los pilares del programa Prensa Escuela}

\section{Lenguaje y formación}

El lenguaje es vital en cuanto da vida a la relación que los seres humanos construyen progresivamente con el mundo que los rodea, y estos crean a su vez una relación con el lenguaje que dota de sentido los estímulos sensoriales y da forma a la cognición; esto implica asuntos como la representación interior de la realidad, la adquisición de una lengua, la comunicación de pensamientos y sentimientos, y es gracias al lenguaje que lo que se llama sociedad, con sus deberes y derechos, puede existir en ese constructo social que se denomina cultura. Larrosa (1998), siguiendo a Nietzsche, enuncia:

El lenguaje y el conocimiento no son otra cosa que productos del instinto de conservación de ese animal débil y poco robusto que es el animal humano y expresiones de su vida sobre la tierra, de sus modos particulares de existencia. Lo que hay en el origen del lenguaje y del conocimiento es una especie de instinto ficcional, radicalmente perspectivista, orientado a la conservación de la vida y, más adelante, al poder. (Larrosa, 1998, p. 72)

Así, el lenguaje acoge, determina y garantiza el mantenimiento de los grupos humanos: designando los conceptos, estableciendo juicios y estructurando la lengua en unas leyes gramaticales, lo que quiere decir que da cuenta de un modo de vida particular. En este sentido, la verdad sobre el mundo no es un asunto absoluto y fijo sino, por el contrario, en constante transformación, y requiere ser aprehendida bajo dicha premisa; es decir que si bien el lenguaje permite representar, expresar y comunicar, no hay una sola forma válida de hacerlo. Y si se tiene en cuenta que la realidad es lingüística, entonces las posibilidades de interpretación de ella se amplían y vigorizan.

En el ámbito educativo el impacto de las ideas anteriores tiene diferentes consecuencias, que afectarían no solo los procesos 
didácticos sino también los de diseño curricular y las leyes educativas; pero teniendo en cuenta que el programa Prensa Escuela rodea dicho ámbito y propone un serie de actividades y logros que atienden a la pluralidad de la experiencia del lenguaje (Larrosa, 1998), es posible darle cabida a una realidad múltiple que existe por y desde el lenguaje, cuyo movimiento es constante, siendo esta característica una ventaja y no una desventaja. Y de allí deviene y se mantiene la preocupación del programa por acercar a los asistentes a esas otras formas de nombrar y por tanto de existir, para poder comprenderlas y posibilitar la coexistencia. En Prensa Escuela es además esencial que haya un lugar para el cuestionamiento de lo establecido, y un espacio para la enunciación de lo propio.

De esta manera, el logro que se espera alcanzar es que haya una reflexión sobre sí mismo, sobre el otro y el mundo, y que al entender la pluralidad se dé valor a lo propio y lo ajeno; esto empieza, y es circundado como un marco, por el lenguaje. Al respecto, Larrosa (1998), retomando a Heidegger, dice que

dada la historicidad y la pluralidad del lenguaje, su dimensión ontológica consiste en su capacidad para abrir no el mundo sino un mundo, y para posibilitar no el yo sino un yo, un determinado modo de subjetividad histórica y culturalmente determinado. (p. 74)

El panorama que el lenguaje da al ser humano es entonces finito en cuanto al marco histórico desde el cual una persona interpreta; dicha acción no puede ser completa debido a la movilidad y diversidad de los fenómenos lingüísticos, y cuando se comprende algo es un acontecimiento (Gadamer, 1997) que tiene un sentido anclado al momento y lugar: se crea una versión de mundo que se acerca a una ficción, a una narración. Este elemento, como se verá más adelante, es clave en Prensa Escuela.

Por otro lado, al programa se asiste como participante de manera voluntaria, y así cobra sentido el concepto de formación, ya que esta es fruto de los esfuerzos y decisiones personales. Los par- 
ticipantes no asisten a una clase regular sobre comunicación y ciudadanía, las actividades no son tareas para alcanzar una nota, y los temas a trabajar son aquellos que más interesan a los asistentes.

Para Gadamer (1997), la formación no consiste en almacenar información, temas, materias; al contrario, el autor señala la necesidad del distanciamiento de un saber para la ampliación de la visión o perspectiva, para poder ver de otra manera; la palabra alemana Bildung designa "el modo específicamente humano de dar forma a las disposiciones y capacidades naturales del hombre" (Gadamer, 1997, p. 39); esto implica que es un proceso individual, interior y en constante desarrollo, es decir, no está acabado; los elementos y estímulos del entorno son la base de la formación pero es la persona quien lleva el timón y elige los puertos tanto de abastecimiento como de descanso.

De esta manera, al otorgar legitimidad, vigencia y valor a modos de vida diferentes se acortan las propias limitaciones y se abre el panorama para las preguntas y las inquietudes; aquí el desconocimiento es una oportunidad y no una desventaja como ya se señaló. La formación implica una apropiación de aquello en lo cual y a través de lo cual una persona se forma (Gadamer, 1997): al reconocer en lo extraño lo propio ocurre el retorno a sí mismo, se establece una conexión. Esa dinámica se pone a prueba en Prensa Escuela cuando se busca que los asistentes puedan ver, escuchar y hablar con el otro, que en esencia es diferente, pero que además viene de un contexto histórico y social desconocido; allí entonces ocurre o bien la interacción y por tanto la disposición para ella, o el cierre hacia aquello que no se sabe qué es. La formación no es querer saberlo todo, es entender que hay cosas que no se saben, manteniendo así la vida humana en movimiento.

Además, la formación se enmarca en la consideración de que la historia y la verdad son asuntos dinámicos y no absolutos; al trascender la particularidad y dirigir la atención más allá de sí mismo, la persona puede acceder a un conocimiento práctico (Grondin, 2003) que cobra sentido en la situación real de la vida cotidiana; en este sentido, no se "enseña" a alguien a formarse, se acompaña 
la reflexión sobre sí mismo y la realidad, se dan herramientas como lecturas, testimonios, espacios de experiencia, pero es la propia persona quien se construye, no habiendo así un estándar o cima sino un proceso, un camino inacabado.

La apertura al reconocimiento personal y del otro es una meta clave del programa, teniendo en cuenta que al lograr una interacción con el mundo y con quienes conforman los grupos humanos, la coexistencia puede adquirir características más armónicas, justas y equitativas; entonces las estrategias pedagógicas de Prensa Escuela se sirven de y son posibles gracias al lenguaje y a la capacidad de formación que comparten los seres humanos.

\section{Construir y dar sentido}

El programa Prensa Escuela recoge los postulados teóricos del modelo constructivista y en especial lo propuesto por Vigotsky, centrándose en primer lugar en el reconocimiento de que el aprendizaje es un proceso social (Vigotsky, 1996), de interacción con el medio y con quienes lo constituyen, donde la experiencia adquiere sentido en un contexto específico que se enmarca además históricamente; esto en consonancia con lo expuesto sobre lenguaje y formación. Lo que quiere decir que el programa se constituye como un espacio de re-encuentro en el cual los asistentes acuden de manera voluntaria con sus propias expectativas e intereses para dialogar con el otro, esta es la esencia de la convocatoria que el programa realiza.

Además, ese otro no son solo los compañeros, sino que son también los textos y los autores, configurándose de esta manera un escenario de intercambio con personas de la misma ciudad, edades cercanas, intereses similares y también otros con visiones distintas, con escritos y escritores que muestran un mundo aún más amplio y abierto, atendiendo a una característica fundamental del constructivismo: "las múltiples representaciones de la realidad evaden las simplificaciones y representan la complejidad del mundo real" (Hernández, 2008, p. 28). 
Es un objetivo central del programa que los asistentes se detengan a pensar sobre su entorno inmediato y puedan volver a valorarlo y sopesarlo al ampliar su perspectiva. Prensa Escuela ofrece elementos a lo largo de las actividades de los talleres que apuntan a devolverle a la cotidianidad su protagonismo, ya que es en ella, con su devenir histórico y social, donde residen las personas, y es fundamental que la construcción de aprendizajes permita habitar en el espacio y tiempo reales. Así se puede dar paso a propuestas de intervención en el medio, más contextualizadas y que vayan más allá de la particularidad.

Aquí sobresale otra premisa del constructivismo que el programa mantiene tanto en el diseño como en la ejecución de sus actividades y es que el sujeto es un participante activo (Vigostky, 1996); la mencionada interacción con el mundo tiene lugar desde la disposición y motivación de la persona, y por tanto la responsabilidad de las decisiones y acciones recae sobre el sujeto mismo. Esto condiciona la construcción del conocimiento en tanto en cuanto pueden darse herramientas y estímulos para ello, pero en última instancia el sujeto escoge un camino; lo que pretende Prensa Escuela es acompañar ese recorrido, orientándolo a mantener una escucha atenta a todo lo que nos rodea, una mirada respetuosa sobre el otro y un diálogo constante consigo mismo.

Dicho acompañamiento implica además el respeto y aprovechamiento de los conocimientos previos de los estudiantes y asistentes sobre la propuesta temática a trabajar. Siendo la lectura y escritura asuntos fundamentales para el aprendizaje, Prensa Escuela ofrece desde esos procesos posibilidades de ampliación y reconfiguración de los pensamientos y acciones regulares: se leen documentos cercanos al contexto, que hablan de la realidad desde puntos de vista diferentes y se brindan espacios de escritura en los cuales la voz del sujeto tiene valor y puede ser escuchada; todo esto para favorecer la convivencia, para que las interacciones sean más beneficiosas para todos.

Teniendo en cuenta el gran valor de las mencionadas interacciones sociales para el aprendizaje, el concepto constructivista de 
zona de desarrollo próximo (Vigotsky, 1996) adquiere sentido en tanto en cuanto gracias a la presencia y ayuda de otro se puede avanzar en la construcción de conocimiento, más allá de un grado o meta que se logra a solas. Esta situación es aprovechada por el programa desde la constitución de los grupos de trabajo: en primer lugar, los talleristas operan generalmente en parejas de diferentes carreras universitarias -Educación y Comunicación social/Periodismo-, lo que les permite poner al servicio de las actividades distintas habilidades y conocimientos; por otro lado, los grupos de estudiantes se componen por personas de diferentes colegios, públicos y privados, de distintos estratos socioeconómicos y contextos diversos.

Todo esto promueve desde el inicio una ampliación del mundo cotidiano, que muchas veces se limita al sector de residencia y estudio, y además permite interacciones novedosas, que pueden apoyar el avance en la comprensión de la realidad y de los aprendizajes necesarios para afrontar los retos del entorno. Cabe aclarar que para el constructivismo ese otro que permite favorecer la zona de desarrollo próximo no es un experto erudito que impone o transmite un saber, lo que ocurre es que gracias a las interacciones sociales una persona que ha avanzado un paso o muchos puede ayudar a otros a dar dichos pasos: todo depende de la disposición de ambas partes, es decir que hay una serie de esfuerzos y tareas por realizar.

En este orden de ideas resalta la importancia del trabajo en conjunto como un escenario fundamental de aprendizaje, pero también es clave que el sujeto le atribuya sentido y significado a lo que hace, allí aparece el aprendizaje significativo propuesto por Ausubel, Novak y Hanesian (1983), continuadores de la línea constructivista, que postulan el enlace indispensable entre lo que ya sabe el estudiante y la nueva información; es a partir de este acoplamiento que el aprendizaje adquiere sentido, ya que los conocimientos previos de una persona fueron construidos en un marco contextual donde son usados y tienen relevancia, así lo nuevo que se aprende también entra a aportar en el desenvolvimiento del sujeto en el mundo, y modifica su estructura cognitiva; esto es lo 
que se conoce como principio de asimilación (Ausubel, Novak y Hanesian, 1983).

Para Prensa Escuela el valor de las ideas, sentimientos, emociones y conocimientos que los asistentes tienen es un punto clave de trabajo, ya que el programa precisamente busca dar relevancia al ser humano en sus diferentes dimensiones, lo que se traduce en la escucha hacia el discurso del otro, en la escritura de las vivencias que han forjado un modo de vida y en la búsqueda del diálogo; se pretende que al compartir un taller, una actividad puntual, una conversación se reconozca el valor de cada uno y se pueda abrir un panorama de aprendizaje extendido.

Ahora, atendiendo a los tres tipos de aprendizaje significativo enunciados por Ausubel, Novak y Hanesian (1983), el "aprendizaje de representaciones" (p. 46), que alude a la equiparación de un símbolo con un concepto o idea, en Prensa Escuela se aprovecha para dotar de significado desde el nombre hasta las actividades del programa, en el cual los asistentes encuentran un espacio distinto al aula de clases regular, es decir que el sentido del programa es construido por los participantes a medida que asisten. Así, cuando hacia el final del ciclo de encuentros se recogen los testimonios orales y escritos una pregunta importante es "¿qué es Prensa Escuela para ti?". De esta manera, se evidencian las distintas formas de apropiación de las actividades y los aprendizajes significativos de los participantes.

Con respecto al "aprendizaje de conceptos" (Ausubel, Novak y Hanesian, 1983, p. 61), que se logra por asimilación, los principales conceptos que se trabajan en Prensa Escuela tienen que ver con los géneros periodísticos y sus características, que los asistentes aplican al construir ellos mismos un texto que puede aproximarse a una crónica, una entrevista o un perfil; además se conceptualizan los elementos que llevan a hacer una lectura con criterio y una escritura con responsabilidad, brindando así un soporte a las elaboraciones y acciones de los estudiantes.

Finalmente, el "aprendizaje de proposiciones" (Ausubel, Novak y Hanesian, 1983, p. 70) demanda el reto de comprensión de pro- 
posiciones en las cuales los conceptos y sus símbolos se integran en un todo coherente $y$, por tanto, exige la elaboración propia de lo asimilado. Este tipo de aprendizaje tiene un lugar importante en Prensa Escuela cuando los asistentes comparten sus escritos al grupo de trabajo, ya que el reconocimiento de los pensamientos y sentimientos que ellos encierran tienen además la forma de un género periodístico, es decir que los estudiantes aplican lo aprendido no solo para la elaboración de un texto sino para la comprensión de los de sus compañeros.

\section{Estrategias para la formación: ¿qué propone Prensa Escuela?}

De acuerdo con los hallazgos de la investigación que sustenta este escrito se identifican con respecto a la ética tres categorías claves: reflexión sobre sí mismo, interpretación de la realidad y fortalecimiento de la autonomía; y con respecto a la formación ciudadana, se reconocen tres aspectos fundamentales: reconocimiento del territorio, problematización de la realidad y narración. Estos son aspectos aptos para traducirse en estrategias pedagógicas que apuntan precisamente a la construcción de la ética y la ciudadanía, por eso se presentan a continuación con las características que adquieren dentro del programa.

\section{Formarse, un asunto ético}

Para que la reflexión sobre sí mismo adquiera un estatus de estrategia de trabajo en Prensa Escuela se la asocia a dirigir la mirada hacia al sujeto en su cotidianidad y a los acontecimientos importantes de la vida que no tienen un parámetro único, sino que su valor es otorgado por quien los vivencia; se acoge la pluralidad de lo humano como una oportunidad de formación:

Una de las exigencias del mundo contemporáneo, en términos éticos, tiene que ver con la mirada pluralista y la 
aceptación e incorporación de la diferencia. La mirada plural exige reconocer al otro como un "sí mismo" pero diferente a uno; en esta sociedad no se trata de la imposición o de la persuasión del otro o de lo otro, sino de la inclusión de las diferencias. (Álvarez, 2012, p. 120)

Aunque los talleres tienen una planeación previa, se realizan considerando los posibles aportes de los asistentes, integran sus intereses y se modifican a largo plazo hacia las motivaciones identificadas, pues en concordancia con lo que señala Giroux (2003), desde una mirada de la pedagogía crítica, el programa se preocupa "por la experiencia del estudiante; toma por punto de partida los problemas y necesidades de los propios estudiantes. Esto sugiere tanto confirmar como legitimar los conocimientos y experiencias gracias a los cuales dan sentido a su vida" (p. 250).

Luego, teniendo en cuenta la importancia de la ubicación espacial y temporal del sujeto, se realizan talleres dirigidos al reconocimiento corporal y de los sentidos, vías ineludibles de reflexión en tanto la relación con el mundo es construida desde ese primer hábitat que es el cuerpo, pues según Le Breton (2002), "del cuerpo nacen y se propagan las significaciones que constituyen la base de la existencia individual y colectiva" (p. 7), recordando que los sujetos sociales, desde su cuerpo, están transmitiendo sentido continuamente, lo cual permite la construcción de distintas interacciones.

Se pretende aprovechar la noción de mirada, de observación, pero aclarando que es una decisión metodológica, porque un ser humano no puede desligar de su percepción del mundo la escucha, la experiencia y demás; en este caso se le da protagonismo a la mirada para explotar su importancia. Así, volver la mirada al sujeto es un requisito clave para la construcción de la ética, que según Foucault (1984) no son patrones universales de conducta, sino un ejercicio reflexionado de la libertad, es decir que las acciones se ejecutan con relación al otro; el ser humano siempre es parte de una comunidad, es a partir de sí mismo que el sujeto convive con los demás. 
Dentro del trabajo de Prensa Escuela es muy importante que los asistentes identifiquen que tienen algo que decir; como dice Giroux (2008), los programas de formación deben "suministrar las condiciones que dan a los estudiantes la oportunidad de hablar con sus propias voces para autenticar sus propias experiencias" (p. 256). Con esto se posibilita la reflexión sobre sí mismo porque cuando las experiencias de los sujetos aparecen en el diálogo y luego se transforman en un relato, estos pueden adquirir "consciencia personal, reflexionar y comprender la realidad social, compartir las ideas personales y valorar las vivencias propias, en la perspectiva de comprometerse con una transformación social" (Ceballos, 2015, p. 80), asunto que más adelante también se verá claramente expresado en el apartado de ciudadanía.

Uno de los principales logros de las actividades de Prensa Escuela es que el sujeto se empiece a hacer preguntas o complejice las que ya lo habitan sobre sí mismo y su entorno, de forma que no sea un receptor pasivo de sucesos sino un agente participativo y se involucre; en el programa estas acciones se orientan a la interpretación de la realidad.

De esta manera, en Prensa Escuela se propicia la elaboración de preguntas en un proceso en que, más allá de un sentido regular de recolectar información o instrucciones, se aprovecha la postura del que interroga para darle un lugar relevante al desconocimiento: "es en el juego de pregunta y respuesta donde ofrece una perspectiva que no se encontraba ni en la mía ni en la del otro" (Gadamer, 1998, p. 146); es decir que, ante la realidad, el ser humano desconoce mucho, pero puede indagar sobre aquello que es importante para la vida, que en el programa y en este caso será aquello que aporte en la construcción de la ética. Por medio de la fabricación de preguntas no solo a personas vivas, sino a personajes representativos, textos y contextos se promueve en los participantes una actitud inquisitiva ante el mundo; la vida cotidiana está llena de eventos y fenómenos que no se comprenden del todo y que por tanto requieren atención; así, la interpretación del mundo es una estrategia que parte de la pregunta. 
Para empezar a detonar en los participantes la tarea de preguntar se utilizan fotografías; para ello las galerías gráficas del periódico son un recurso importante ya que ilustran trozos de contextos cercanos y globales; no siendo común la elaboración de preguntas a una imagen, los asistentes se ven llevados a la observación de detalles, lectura de signos, otorgamiento de sentido y reconstrucción de momentos y lugares, todos asuntos fundamentales para la interpretación del mundo, que, es conveniente aclararlo, está en continuo movimiento y no posee una versión única: "es evidente que los seres humanos experimentamos la realidad de formas diversas, pero siempre de manera cambiante" (Mèlich, 2003, p. 37).

Así, se pretende que los asistentes efectúen múltiples miradas al mundo que los rodea, avancen de su particularidad al reconocimiento de un todo permitiéndose dotar con nuevos significados símbolos que encuentra en su entorno. Luego se pasa a hacer preguntas a las personas de la cotidianidad para lograr una comprensión de ellas, y muy importante, su valorización; aquí el género de la entrevista sirve para configurar el acercamiento al otro.

La construcción de la ética se nutre de esta indagación y comprensión, pues pone en perspectiva los modelos regulares o populares de un contexto con aquellos que adquieren protagonismo gracias a la indagación por modos de vida distintos, y que conviven diariamente en una sociedad; así, personas como quien atiende en la cafetería, hace el aseo del colegio, barre las calles de la ciudad, entre miles de otras pasan a ser vistas y reconocidas.

Cuando en el encuentro presencial los participantes comparten sus hallazgos e indagaciones y los acontecimientos que rodearon sus pesquisas termina de configurarse un espacio que da cabida a las múltiples versiones que un hecho de la realidad o un personaje puede tener; es decir que no hay una sola versión válida o universal para entender el mundo, al contrario, las maneras de hacerlo son múltiples; aquí lo que el programa promueve es que se argumente la relevancia, pertinencia y fiabilidad de lo expuesto, sustentando además su importancia respecto a las acciones éticas y de formación que sus propuestas tienen; cuando los participantes pasan a 
la escritura, ya sea tipo entrevista, crónica o perfil, su intención es clara: contribuir a la visibilización de sucesos y personas que aportan positivamente a la sociedad.

Ahora, estos procesos de reflexión sobre sí mismo y de interpretación de la realidad pueden fortalecer la autonomía al posibilitar una toma de decisiones reflexionada, contextualizada y que integra lo colectivo y trasciende lo particular sin desatender la postura del sujeto; para ello la lectura constante de noticias, reportajes, crónicas, fotografías, entre otros, es fundamental: "La autonomía se desarrolla superando, en primer lugar, nuestra ignorancia. Ello significa estar informados, saber informarse, conocer las posibilidades y las limitaciones propias y ajenas" (Otero, 1990, p. 123); por eso es parte de los talleres la recolección de información sobre eventos del momento, su devenir histórico y las repercusiones a largo plazo; a partir de esto la conversación para la confrontación de argumentos es una tarea regular de los talleres.

Es esencial considerar el papel que tienen los medios de comunicación en la sociedad actual; por ejemplo, pueden abrir el horizonte de los estudiantes, entendiendo que estos medios tienen gran facilidad para "adecuarse a los cambios de la sociedad y para impulsar múltiples formas nuevas de comprender y hacer la vida en su misma cotidianeidad", como dice Germán Rey (citado por Rodríguez, 2004, p. 188); por eso el objetivo del programa es mostrar distintos contenidos que se producen en la prensa y la red pero siempre con el objetivo de propiciar la reflexión sobre el poder que tienen estos medios para construir y representar realidades, y a la vez señalar su capacidad para trasmitir modos de ser.

A la par que se les ofrece a los asistentes escritos, medios y experiencias, son ellos quienes seleccionan por sí mismos los temas a trabajar, o en otras palabras, para escribir y vivenciar. La premisa que se ofrece desde el programa es buscar aquello que tiene impacto en sus vidas; en ese ejercicio se muestran sus preocupaciones y prioridades, además pueden exponer sus puntos de vista y evidenciar sus necesidades, o como menciona Larrosa (abril de 2008), "las aulas son, o han sido a veces, o podrían haber sido, 
lugares de la voz, porque en ellas los alumnos y los profesores tenían que estar presentes" (p. 5); y es de esta manera como el programa insiste en recuperar la participación del estudiante, que con su presencia ya está transmitiendo mucho, para avanzar en el enriquecimiento de su discurso.

Prensa Escuela busca seguir una de las premisas de Freinet (2005) con los participantes respecto a escribir para que otros puedan reconocer algo, es decir que la escritura es un proceso que involucra al otro. Este asunto es fundamental en el desarrollo de la autonomía de los estudiantes porque la reflexión que propicia el programa va encaminada a reconocer que cada texto que escriban o cada palabra que pronuncien los jóvenes se constituye en una decisión importante, con consecuencias sobre sí mismo, y sobre quien lee y escucha; se pretende así fortalecer la responsabilidad. La posibilidad de una publicación física o digital convierte los textos en un producto social e incluso en una manifestación de la memoria de un momento relevante en la vida (Ceballos, 2015).

Con todo esto, se espera que la toma de decisiones en la vida diaria se vea permeada por estos procesos, que haya una construcción de criterios, ya que, como lo indica Álvarez (2012),

la autonomía es algo que se alcanza con el paso del tiempo, y se es autónomo en la medida en que se es capaz de dictar las propias normas, en que no se necesita de instancias reguladoras o sancionatorias para hacer las cosas; la autonomía va íntimamente ligada con el uso adecuado de la libertad y con el sentido de la responsabilidad que se tiene frente a las cosas. (p. 121)

Es decir, se busca que los aprendizajes obtenidos en los talleres llenen los espacios y situaciones de la vida para avanzar en el camino de las transformaciones sociales que los habitantes del país necesitan, tanto para crecer como para convivir. 


\section{Transformación social, meta clave de la formación ciudadana}

Es innegable la relación que guardan las anteriores categorías con la formación ciudadana; sin embargo, se hace esta diferenciación con el fin de mostrar las características que tienen dentro del programa Prensa Escuela, señalando que en el desarrollo de las labores el abordaje de la ética y la formación ciudadana se hace en conjunto, y que los talleres integran dichos temas para su mutuo enriquecimiento. A continuación, aparecen tres de los puntos centrales identificados para este apartado como estrategias de trabajo: reconocimiento del territorio, problematización de la realidad y narración.

La noción de reconocimiento del territorio que se transmite en el programa se piensa en colectivo. Como se mencionó antes, las personas hacen parte de un grupo y allí construyen su manera de habitar el mundo, su cultura; entonces el Programa pretende reconocer el valor de las tradiciones y apoyar la modificación de patrones de violencia o conflicto, para que los participantes busquen otras maneras de habitar en Colombia que sean más acordes a los retos y necesidades de su región y del mundo. El concepto de ciudadano territorial de Gutiérrez (2010) ilustra aquí esa necesidad de recuperar lo necesario para habitar en el país, ya que

este no nace, sino que se hace, es necesario formarlo en contexto, de manera consciente e intencionada, para que ligado al territorio que habita, construye y semantiza, pueda desplegar junto a otros una ciudadanía renovada orientada al respeto por la diferencia, al reconocimiento de la pluralidad, a la construcción de convivencia y, consecuentemente, a aportar en la consolidación de la democracia. (p. 1)

Actividades para la identificación de lugares comunes y ajenos en el barrio y en la ciudad facilitan la indagación por la historia y por las diferentes narraciones que ya existen sobre esos espacios. Una actividad representativa al respecto y que Prensa Escuela 
propone para la formación ciudadana es la visita a comunas de la ciudad, museos, fundaciones, corporaciones, teatros, parques y demás espacios que están contribuyendo continuamente para que la ciudad se lea desde diversas perspectivas, donde la paz, el arte y la convivencia adquieren mayor relevancia. Esto va en consonancia con algunas iniciativas de recorridos por la ciudad de algunas entidades públicas, los cuales facilitan el reconocimiento de algunas facetas de la urbe que han sido opacadas por el conflicto durante años y que reclaman la atención de todos los ciudadanos.

Es importante mencionar, además, que para el reconocimiento del territorio adquieren un papel fundamental las imágenes: volver a los mapas, a las fotografías, infografías o ilustraciones de un lugar, para ubicarse en el territorio y conocer lo que en este sucede, para entender su historia; es una manera de acercarse a la ciudad en los casos en que no se tenga la posibilidad de recorrerla; para esto la prensa se postula (en sus múltiples plataformas) como un recurso clave.

Unido a lo anterior, la lectura grupal en voz alta de crónicas y perfiles es una actividad importante dentro del programa, la cual sigue reforzando lo expuesto: ampliar la perspectiva sobre un tema, lugar o persona. Un objetivo puntual al respecto es que por medio de los géneros periodísticos se dé a conocer a los participantes figuras relevantes del contexto regional y mundial que aboguen por la convivencia y sean modelos de formación ciudadana; esto integra artistas, músicos, académicos, deportistas, entre otros, de manera que al escuchar sus historias se pueda hacer acopio de elementos para la propia formación y se reconozcan las diversas maneras como se puede aportar en la construcción de una sociedad mejor.

De esta forma se orienta la atención de los asistentes a la búsqueda de opciones de vida, y a la identificación de elementos y acontecimientos sociales que muchas veces pasan desapercibidos, hacia conflictos que se han normalizado y hacia personajes que se han invisibilizado. 
Como se ha venido explicando, las actividades de todo el ciclo de El Taller procuran integrar la construcción de la ética y la formación ciudadana; entonces es conveniente aclarar aquí que la problematización de la realidad implica un reconocimiento previo de ella, un cuestionamiento de lo establecido $y$, muy importante, proponer caminos de mejoramiento o vías de solución, porque "la educación tiene que necesariamente preguntarse por los mundos culturales de los sujetos a los cuales pretende formar" (Huergo, 2011, párr. 59); es decir, la formación no puede desentenderse de lo cotidiano, de la cultura que es el marco de referencia para entender el mundo de cada persona, el que llena de significados la realidad; una realidad que también se puede re-significar, de manera que los asistentes vuelvan a mirar su vida, sus experiencias, lo que les sucede no como naturaleza muerta, diría Tomás Eloy Martínez (1997), sino como un relato.

Para ello, se realizan también actividades de exploración guiada de entornos cercanos, tanto aquellos que hacen parte de los lugares donde se ejecutan los talleres, como los de cada persona en su vida diaria; con base en ejercicios experienciales, tipo juegos de pistas y roles, los asistentes aplican lo discutido sobre la postura abierta, de observación y escucha de un buen periodista para identificar aspectos de la realidad potencialmente problemáticos o conflictos concretos, pues "el hacer periodístico no solo es el resultado de una reflexión y una deliberación previas a la resolución de informar, orientar y explicar, sino el fruto de un compromiso" (Martínez, 2008, p. 306).

Esto quiere decir que se aprovechan los conceptos y prácticas del periodismo para fortalecer una postura reflexiva y exploratoria del mundo; los asistentes tienen en mente que escribirán sobre dichas experiencias, que serán leídos por otros; además, se busca que estos ejercicios propongan una interpretación del mundo que abogue por el bien colectivo.

De ahí que el desarrollo de competencias capacite al ciudadano para que problematice su realidad y sepa en qué consiste una decisión que construye solidaridad y sentido 
de pertenencia público. El ciudadano es el que descubre en lo cotidiano cuáles son las preguntas, se cuestiona sobre las reglas y descubre la racionalidad de seguirlas, ojalá por la vía de combinar cultura, ley y valores. (Borrero, 2006, p. 203)

Dichas propuestas se cifran en la narración, por eso en Prensa Escuela la escritura es una estrategia de intervención social, en concordancia con lo que enuncia Larrosa (2006):

Escribir es una de las formas que tenemos para estar atentos al mundo y a lo que nos pasa. Escribir forma parte de una tentativa para ser parte del mundo de una forma más reflexiva, más consciente, más plena, más intensa. Escribir forma parte de ese esfuerzo, nunca garantizado, por estar presentes en lo que nos pasa. (p. 7)

Además, como diría Bacher (2009), es crucial que los jóvenes puedan descubrir el poder de la palabra: "que la perciban como herramienta para la transformación del tiempo en el que viven y que comprendan que ejercer el derecho a la comunicación es una oportunidad para establecer vías de participación ciudadana, de reflexión y creatividad" (p. 117). Por eso en Prensa Escuela la conversación es el eje de cada taller, una metodología fundamental en la que, como se expresó al principio, el conocimiento es una construcción de todos los que participan, y que se ubica como antecedente indispensable de la escritura; cada encuentro es un espacio para la palabra, siguiendo la idea de Freire (1985), quien propone el diálogo como un encuentro en el que se da la reflexión y la acción de los sujetos que pronuncian el mundo para transformarlo.

La palabra le posibilita al sujeto percibirse como protagonista de su propia historia y de su realidad y, por lo tanto, hacerse más responsable de esta; como diría Fiori (1985) sobre el pedagogo brasileño: "Tal vez sea ese el sentido más exacto de la alfabetización: aprender a escribir su vida, como autor y como testigo de su historia -biografiarse, existenciarse, historizarse" (p. 5). Además, esto es trascendental para cualquier persona y no solo para aque- 
Ilos que se quieran dedicar a ser escritores, porque la narración tiene un potencial enorme para comprender la realidad, le otorga significado a las acciones y legitima lo que acontece; es por eso que esta estrategia es una de las más contundentes que se usa en Prensa Escuela, cuyo objetivo no es que puedan pensar en orden, sino construir su identidad, crear memoria, reflexionar sobre su futuro y "encontrarle sentido a nuestro estar en el mundo" (Rincón, 2006, p. 90).

Para este caso la estructuración de una escritura veraz, de acuerdo con los géneros periodísticos, es la guía de trabajo, en tanto en cuanto es capaz de mostrar la parte del mundo que contiene desde la perspectiva de su autor e integrar la realidad colectiva, pues "la cultura del estudiante es el reflejo de la cultura social de su comunidad, mediatizada por su experiencia biográfica, estrechamente vinculada al contexto" (Pérez, 1998, p. 199). Así que gracias a la retrospectiva que brinda escribir sobre asuntos del pasado, se pueden interpretar los hechos para que sean mejor comprendidos tanto por quien escribe como por quien lee.

Vale la pena recordar en este punto a Martín-Barbero (2001, citado en Valderrama, 2010) cuando dice: "Muchas de las posibilidades de ser reconocidos, tenidos en cuenta, contar en las decisiones que nos afectan, dependen de la veracidad y legitimidad de los relatos en que contamos, la tensión entre lo que somos y lo que queremos ser" (p. 286); aquí entra en relación una noción importante propuesta por Martha Nussbaum (2015) sobre imaginación narrativa, quien la explica así:

Aprender a ver a otro ser humano no como una cosa sino como una persona completa, no es un logro automático: debe ser promovido por una educación que refine la capacidad de pensar acerca de lo que puede ser la vida interna de otro y también para entender por qué no es posible captar plenamente ese mundo interior, por qué una persona es siempre hasta cierto punto un enigma para el otro. (párr. 35) 
Cabe aclarar que, si bien se trabajan escenarios de conflicto, dolor y muerte, los textos no tienen un tono de lamento o reproche; son la manifestación de una vivencia que se comparte, como se dijo, con la intención de evidenciar otras formas pacíficas de resolución de conflictos, muestran las apuestas de los jóvenes para transformar su realidad en pro de lo comunitario desde su aporte personal. De esta manera, el sujeto vuelve a encontrarse a sí mismo en la narración, como habitante de un territorio, alguien con vínculos sociales propiciados por la escucha, y cuya intervención en su entorno está mediada por sus derechos y los de quienes lo rodean.

Así mismo, es en la relación que se produce entre el lector y el texto narrativo donde se fortalece la empatía, característica esencial del ciudadano (Chaux, 2005); por eso se leen de acuerdo al tema del taller los escritos publicados en años anteriores por otros jóvenes de edades similares y anhelos parecidos, para que sigan perdurando las palabras y acciones de sus autores en el ejercicio de formarse como ciudadanos, pues como diría Hayden White (citado por Martínez, 1997): "Podemos no comprender plenamente los sistemas de pensamiento de otra cultura, pero tenemos mucha menos dificultad para entender un relato que procede de otra cultura, por exótica que nos parezca" (p. 6).

\section{Conclusiones}

Al empezar el milenio, Martín-Barbero (2003) propuso la necesidad de pensar el lugar estratégico que tiene hoy la comunicación en la configuración de nuevos modelos de sociedad. Prensa Escuela se ha propuesto reflexionar sobre esta premisa para aplicarla desde los procesos de formación que lleva a cabo cada año, y considerando que el mundo de hoy se presenta mediado por las tecnologías de la información, que han introducido grandes cambios en las maneras de entender la educación, la política o la economía, por lo cual es pertinente precisar que la problemática de la comunicación no se reduce a los medios ni a los aparatos (Huergo, octubre de 2001, p. 90), sino que se entiende como un acto de poner en 
común con el otro, lo que puede traducirse como una manera de participación dentro de una sociedad.

El encuentro y posible articulación entre el campo de la comunicación y de la educación es un terreno cultural, político y ético, y no solamente un campo tecnológico, donde además de las nuevas construcciones de los saberes y disciplinas demandadas por la sociedad de la información, se exige, sobre todo, la construcción de una ciudadanía para la democracia y la paz. (Rodríguez, 2004, p. 188)

Ahora bien, Prensa Escuela se centra en el hecho de que la comunicación ha introducido grandes cambios en la educación, lo cual le plantea grandes retos al sistema porque el conocimiento está descentralizado, cada vez más la manera de acceder al saber pasa por una búsqueda en Google que por la consulta a un profesor, lo cual a su vez introduce un nuevo acto de socialización, como propone Martín-Barbero (2011). Esto plantea un reto cultural a cada proceso de formación porque son los medios de comunicación y las tecnologías de la información los que se convierten en plataformas por donde circula no solo el conocimiento, sino también estilos de vida. Por eso, la propuesta que hace el programa desde este artículo es la implementación de estrategias que, desde la comunicación, complementen los procesos educativos.

Así, la propuesta es poder asumir la comunicación como un hecho cultural, un elemento crucial que permite la construcción de sentidos; como dice María Cristina Mata (1985), "la comunicación representa el espacio donde cada quien pone en juego su posibilidad de construirse con otros" (p. 39), es decir, alejarse del modelo informacional en el que hay un emisor (una persona que trasmite un mensaje) y un receptor (un individuo o grupo que recibe la información) y se pasa a considerar que nadie recibe mensajes aislados, todos están insertos en un entramado sociocultural que hace que cada dato se pueda encadenar con otro y estar creando, todo el tiempo, nuevos significados. 
Por eso, para los procesos de construcción de la ética y de formación ciudadana es fundamental un enfoque comunicativo que consista en el fortalecimiento de la "capacidad para comprender y producir enunciados adecuados con intenciones diversas de comunicación en contextos comunicativos heterogéneos" (Zebadúa y García, 2012, p. 20). Se requiere propiciar un escenario en el cual las habilidades de escucha, observación, habla, lectura y escritura se pongan al servicio de la formación del sujeto en su vida cotidiana, para que pueda afrontar los retos de su entorno desde una postura reflexiva, en la que haya lugar al diálogo y a la resolución pacífica de conflictos. En esta línea, Chaux (2005) propone la asertividad como competencia básica de la formación ciudadana en Colombia ya que esta "permite defender los derechos, de manera cuidadosa y respetuosa con el otro, y es una manera de responder pacíficamente a una agresión. De alguna manera el otro queda desarmado y uno no está respondiendo con más agresión" (p. 139).

Esto conlleva la trasformación de la figura de quien guía el proceso formativo (que tradicionalmente se ha entendido como una persona que meramente retransmite el conocimiento Martín-Barbero, 2011), para que pase a ser alguien capaz de construir sentidos con los otros sujetos, problematizar la realidad, provocar preguntar en los jóvenes y permitir una conversación entre ellos donde se pongan en común sus experiencias, recuerdos, sensibilidades y saberes; en resumen: poder comunicar.

De esta manera, aprovechar las llamadas habilidades comunicativas significa que se realizan acciones, prácticas concretas que impactan la realidad inmediata e incluso la periférica, las cuales son además histórica y socialmente contextualizadas. Valderrama (2007) señala que "argumentar y contraargumentar mediante el análisis y la comprensión de lo que dice el otro es una condición ineludible para la vida en común" (p. 186), siendo esa la vía para el encuentro y la coexistencia.

Además, ante las circunstancias del mundo actual de globalización y consumismo se requiere un trabajo con los jóvenes, como señala Martín-Barbero (2003), ya que ellos "sienten que la sociedad 
no tiene derecho a pedirles una estabilidad que no confiere ninguna de las grandes instituciones modernas: la política, el trabajo y la escuela" (p. 6); entonces se hace urgente construir una postura y criterios para la recepción masiva de información. Los medios de comunicación son muy importantes en este sentido, pero todo empieza desde las maneras de relación con el otro, en las interacciones sociales de la vida diaria, desde las cuales se construye la ética y se fortalece la formación ciudadana.

Así, Prensa Escuela se estructura bajo la noción que propone Kaplún (2002) de educomunicación, en la cual se reconoce que toda acción educativa requiere un proceso de comunicación, por lo que esta última no concierne solo a los profesionales que la han estudiado, sino que también corresponde al trabajo en el aula. Sin embargo, este autor busca alejarse de la concepción de la educación (y de la comunicación) como mera trasmisión de contenidos o como manipulación para lograr que los sujetos se incorporen al sistema al moldear su conducta de acuerdo a unos objetivos, puesto que, para él, "producimos nuestros mensajes 'para que los destinatarios tomen conciencia de su realidad', o 'para suscitar una reflexión', o 'para generar una discusión'" (Kaplún, 2002, p. 15); esto porque la educación es un proceso en el que hay un encuentro entre sujetos que todo el tiempo están reconstruyendo sentidos dentro de la cultura; por eso es que, como dice Barbas (2012, p. 165), la educomunicación tiene "como finalidad la construcción y creación colectiva a través del intercambio simbólico y el flujo de significados".

De esta manera, es importante aceptar que cualquier intercambio comunicativo puede intervenir directamente en la formación de los sujetos; especialmente en la actualidad esto se evidencia con los medios de comunicación y las redes sociales. Es la educomunicación la que permite interactuar con estas redes, concibiendo que haya una conexión entre los saberes y la vida cotidiana de cada uno de los participantes, pero además para que cuestionen esos nuevos formatos de interacción y, por último, se creen otras maneras posibles de enseñar en los diversos espacios que unan los intereses de los estudiantes, pues volviendo a Kaplún (2002), "lo 
que el sujeto educando necesita no es solo ni únicamente datos, informaciones, sino instrumentos para pensar, para interrelacionar un hecho con otro y sacar consecuencias y conclusiones para construirse una explicación global, una cosmovisión coherente" (p. 46).

Todo lo anterior permite concluir que, en palabras de Mata (1985), "la comunicación es, consecuentemente, terreno de modelación social y, por ende, terreno de disputas y negociaciones, conflictos y acuerdos del orden del sentido" (p. 45), por lo cual la propuesta de trabajo de Prensa Escuela y las estrategias pedagógicas aquí enunciadas se centran en la posibilidad de unir los dos campos: comunicación y educación. Su aprovechamiento estará sujeto al contexto, lugar, momento y disposición de los participantes; en este sentido, permanecen abiertas para adaptaciones y enriquecimientos, pues retomando las palabras de Daniel Prieto Castillo (2003), "el hecho educativo es profunda, esencialmente comunicacional, en tanto somos seres de relación, siempre entre y con los otros, no podemos soñar con trasformaciones educativas sin jugar hasta las entrañas nuestra necesidad y capacidad de comunicarnos" (p. 3); el camino está pensado pero su recorrido implica movimiento, intercambio y escucha atenta.

\section{Referencias bibliográficas}

Álvarez, H. M. M. (2012). La autonomía: principio ético contemporáneo. Revista Colombiana de Ciencias Sociales, 3(1), 115-132.

Ausubel, D. P., Novak, J. D. y Hanesian, H. (1983). Psicología educativa: un punto de vista cognoscitivo (vol. 2). Ciudad de México: Trillas.

Barbas, Á. (2012). Educomunicación: desarrollo, enfoques y desafíos en un mundo interconectado. Foro de Educación, 14, p. 157-175.

Bacher, S. (2009). Tatuados por los medios. Dilemas de la educación en la era digital. Buenos Aires: Editorial Paidós. 
Borrero, C. (2006). Ciudadanía social activa: de los problemas a las opciones. En: Comprensiones sobre ciudadanía: veintitrés expertos internacionales conversan sobre cómo construir ciudadanía y aprender a entenderse (pp. 201-212). Bogotá: Ministerio de Educación Nacional y Editorial Magisterio.

Ceballos, J. C. (2015). Medios de comunicación escolar, educación y ciudadanía. Una mirada desde las mediaciones (tesis de doctorado). Universidad de La Plata, Argentina.

Chaux, E. (2005). Cotidianidad, individuo y ciudadanía. En: Comprensiones sobre ciudadanía: veintitrés expertos internacionales conversan sobre cómo construir ciudadanía y aprender a entenderse. (pp. 135-146). Bogotá: Ministerio de Educación Nacional y Editorial Magisterio.

Foucault, M. (20 de enero de 1984). La ética del cuidado de sí como práctica de la libertad. Entrevista con $\mathrm{H}$. Becker, R. Fornet-Betancurt y A. Gómez-Müller. Concordia, Revista Internacional de Filosofía, 6, p. 99116.

Freinet, C. (2005). Técnicas Freinet de la escuela moderna. Mexico: Siglo XXI.

Freire, P. (1985). Pedagogía del oprimido. Ciudad de México: Siglo XXI.

Gadamer, H.-G. (1997). Verdad y método. Salamanca: Sígueme.

Gadamer, H.-G. (1998). El giro hermenéutico. Madrid: Cátedra.

Giroux, H. (2003). La escuela y la lucha por la ciudadanía (3. a ed.). Ciudad de México: Siglo XXI.

Giroux, H. (2008). Teoría y resistencia en educación (7.a ed.). Ciudad de México: Siglo XXI.

Grondin, J. (2003). Introducción a Gadamer. Barcelona: Herder. 
Gutiérrez, A. L. (2010). El ciudadano territorial: propósito de la formación ciudadana. Uni-pluri/versidad, 10(3), 1-12.

Hernández, S. (2008). El modelo constructivista con las nuevas tecnologías: aplicado en el proceso de aprendizaje. RUSC: Universities and Knowledge Society Journal, 5(2), 26-35.

Huergo, J. (2011). Comunicación/educación: un acercamiento al campo. Documento de cátedra: Comunicación y Educación, Facultad de Periodismo y Comunicación Social, UNLP. Recuperado de https://bit. ly/2Tlo9vw

Huergo, J. (Octubre de 2001). Desbordes y conflictos entre la cultura escolar y la cultura mediática. Nómadas, 15, 88-100.

Kaplún, M (2002). Una pedagogía de la comunicación (el comunicador popular). La Habana: Caminos.

Larrosa, J. (1998). Lenguaje y educación. En R. Gil (coord.), Filosofía de la educación hoy: temas (pp. 68-80). Madrid: Dykinson.

Larrosa, J. (2006). Una invitación a la escritura. Revista Propuesta Educativa, 12.

Larrosa, J. (Abril de 2008). Aprender de oído. Intervención en el ciclo de debates Liquidación por derribo: leer, escribir y pensar en la universidad, La Central, Barcelona, España.

Le Breton, D. (2002). La sociología del cuerpo. Buenos. Aires: Nueva Visión.

Martín-Barbero, J. (2003). Saberes hoy: diseminaciones, competencias y transversalidades. Revista Iberoamericana de Educación, 32, 17-34.

Martín-Barbero, J. (2011). Los oficios del comunicador. Signo y Pensamiento, 59, 18-40. 
Martínez, A. (2008). Juegos del periodismo. Investigación y desarrollo, 16(2), 302-325.

Martínez, M. (2006). La investigación cualitativa (síntesis conceptual). Revista de Investigación en Psicología, 9(1), 123-146.

Eloy Martínez, T. (Octubre de 1997). Periodismo y narración: desafíos para el siglo XXI. Conferencia ante la asamblea de la Sociedad Interamericana de Prensa. Guadalajara, México. Recuperado de http://bit.ly/2sukrf7

Nussbaum, M. (2015). Discurso de Martha Nussbaum al recibir el Doctorado Honoris Causa en Filosofía en la Universidad de Antioquia, el 10 de diciembre de 2015. Recuperado de http://reservas.parqueexplora. org/visitenos/noticias/discurso-de-martha-nussbaum-al-recibir-eldoctorado-honoris-causa-en-udea.

Mata, M. (1985). Nociones para pensar la comunicación y la cultura masiva. Módulo 2, curso de especialización Educación para la Comunicación, La Crujía. Buenos Aires. Recuperado de https://bit. ly/2e84KUV

Mèlich, J. C. (2003). La sabiduría de lo incierto: sobre ética y educación desde un punto de vista literario. Educar, 31, 33-45.

Otero, F. (1990). Autonomía y autoridad en la familia. Pamplona: Eunsa.

Pérez, A. (1998). La cultura escolar en la sociedad neoliberal. Madrid: Morata.

Prieto, D. (Julio de 2003). Presencia de la comunicación educativa. Recuperado de https://bit.ly/2B5c6l2

Rincón, O. (2006). Narrativas mediáticas: o cómo se cuenta la sociedad del entretenimiento. Barcelona: Gedisa.

Rodríguez, J. (2004). Medios y tecnologías de la información y la comunicación: una caracterización de las prácticas en instituciones escolares de Bogotá. Revista Colombiana de Educación, 46, 186-218. 
Valderrama, C. E. (2007). Ciudadanía y comunicación: saberes, opiniones y haceres escolares. Bogotá: Siglo del Hombre.

Valderrama, C. (2010). Ciudadanía y formación ciudadana en la sociedad de la información: una aproximación desde la comunicación-educación (pp. 281-306). En R. Aparici (coord.), Educomunicación: más allá del 2.0. Barcelona: Gedisa.

Vigotsky, L. S. (1996). El desarrollo de los procesos psicológicos superiores. Barcelona: Crítica.

Zebadúa, M. D., \& García, E. (2012). Como enseñar a hablar y escuchar en el salón de clases. México: Universidad Nacional Autónoma de México. Recuperado de: https://portalacademico.cch.unam.mx/materiales/ libros/pdfs/librocch_hablarescuchar.pdf 1(2), 3. 